\title{
Strategic Human Resources Management: Where Do We Go From Here?
}

\author{
Brian E. Becker* \\ School of Management, State University of New York at Buffalo, Buffalo, NY 14260 \\ Mark A. Huselid \\ School of Management and Labor Relations, Rutgers University, Piscataway, NJ 08854
}

The authors identify the key challenges facing strategic human resource management (SHRM) going forward and discuss several new directions in both the scholarship and practice of SHRM. They focus on a clearer articulation of the "black box" between HR and firm performance, emphasizing the integration of strategy implementation as the central mediating variable in this relationship. There are direct implications for the nature of fit and contingencies in SHRM. They also highlight the significance of a differentiated HR architecture not just across firms but also within firms.

Keywords: strategy; human resources; black box; implementation; differentiation

The field of strategic human resources management (SHRM) has enjoyed a remarkable ascendancy during the past two decades, as both an academic literature and focus of management practice. The parallel growth in both the research literature and interest among practicing managers is a notable departure from the more common experience, where managers are either unaware or simply uninterested in scholarly developments in our field. As the field of HR strategy begins to mature, we believe that it is time to take stock of where it stands as both a field of inquiry and management practice. Although drawing on nearly two decades of

\footnotetext{
†We are grateful to Steve Frenkel, Dave Lepak, and seminar participants at Monash University for comments on an earlier version of this article.
}

*Corresponding author. Tel.: 716 645-3235.

E-mail address: bbecker@buffalo.edu

Journal of Management, Vol. 32 No. 6, December 2006 898-925 DOI: $10.1177 / 0149206306293668$

(c) 2006 Southern Management Association. All rights reserved.

898 
solid academic progress, this exercise is explicitly prospective. This article is not intended as an encyclopedic analysis of prior work (see Becker \& Huselid, 1998, for an earlier review); instead, it will emphasize what we believe should be the future direction of the field during the next decade.

We begin with the most pressing theoretical challenge facing SHRM, a useful articulation of the "black box" that describes the strategic logic between a firm's HR architecture and its subsequent performance. How does the logic of this "black box" explain HR's contribution to a firm's sustained competitive advantage? Following recent work in the strategy literature, we call for a new emphasis on strategy implementation as the focal mediating construct in SHRM. Specifically, we argue that it is the fit between the HR architecture and the strategic capabilities and business processes that implement strategy that is the basis of HR's contribution to competitive advantage. This will require an increasing level of differentiation of the HR architecture (Lepak \& Snell, 1999), both within the firm and between firms.

Next we address the challenges facing future empirical work. That discussion is divided into two broad sections. First we consider the empirical implications of the proposed emphasis on strategy implementation. We highlight the need for new measures of intermediate outcomes and the importance of estimating HR's impact in managerially significant terms. Second, we examine recent challenges to the magnitude of HR's estimated effect on firm performance in prior work. Although we agree that questions of measurement error, omitted variable bias, and mutual causation should be explored, recent studies that have examined these issues tend to raise more questions than they answer.

This theoretical and empirical foundation highlights several new directions in SHRM research. In the next section, we extend this discussion of a future research agenda to several related questions. This agenda is organized around four broad research questions and considers both the theoretical and empirical implications of our analysis. In several cases, the questions and the methods mark a significant departure from past work in SHRM. Finally, we will assess the state of SHRM practice, both the remarkable progress and the significant hurdles facing HR managers looking to implement these ideas.

\section{SHRM Theory-A New Emphasis}

The field of HR strategy differs from traditional HR management research in two important ways. First, SHRM focuses on organizational performance rather than individual performance. Second, it also emphasizes the role of HR management systems as solutions to business problems (including positive and negative complementarities) rather than individual HR management practices in isolation. But strategic means more than a systems focus or even financial performance. Strategy is about building sustainable competitive advantage that in turn creates above-average financial performance. The simplest depiction of the SHRM model is a relationship between a firm's HR architecture and firm performance. The HR architecture is composed of the systems, practices, competencies, and employee performance behaviors that reflect the development and management of the firm's strategic human capital. Above-average firm performance associated with the HR architecture reflects the quasi rents associated with that strategic resource. 
For the most part, prior SHRM theory has focused on the nature of the HR architecture. What is the nature of the appropriate HR system (i.e., single practices or systems)? What are the key mediating variables (i.e., commitment) within the HR architecture? The architectural metaphor (Becker \& Gerhart, 1996; Becker \& Huselid, 1998, Lepak \& Snell, 1999; Wright, Dunford, \& Snell, 2001) is important because it highlights the locus of value creation in SHRM. Although strategic human capital is reflected in the "human" assets in the organization, it is created and managed through the organizational system reflected in the HR architecture.

The notion of the HR architecture as a value-creating system raises the question of the appropriate locus of strategic value creation. Emphasis in the SHRM literature ranges from the HR system, the resulting workforce skills and competencies, employee commitment and engagement, to employee performance. Within this architectural framework, we would emphasize the importance of the HR system as the most important strategic asset. First, it is the source of value creation in the subsequent outcomes in the HR architecture. Second, it has the potential for greater inimitability based on how it is aligned with the firm's strategy. Finally, unlike human capital, it is immobile.

With a few exceptions (Becker \& Huselid, 1998; Huselid, Beatty, \& Becker, 2005; Huselid, Becker, \& Beatty, 2005; Wright et al.), there has been little effort to extend SHRM theory in a way that formally integrates the mechanism through which the HR architecture actually influences firm performance. Gerhart (2005), for example, has recently suggested that SHRM move closer to the individual level by emphasizing HR's impact on employee relations and attitudes. The heavy focus on the character of the HR architecture is the natural comfort zone of HR scholars. Going forward, however, we need more theoretical work on the "black box" between the HR architecture and firm performance, and less emphasis on the "black box" within the HR architecture. The theoretical literature is out of balance. SHRM is an intermediate or mesotheory, and as such, it draws as much on the strategy literature as the HR literature. Recent developments in the strategy literature, however, suggest a particularly valuable direction for theoretical work in SHRM.

\section{A New Emphasis on Strategy Implementation}

The resource-based view (RBV) of the firm has long provided a core theoretical rationale for HR's potential role as a strategic asset in the firm (Wright \& McMahan, 1992). The notion that organizations can build competitive advantage, and as a result above-average financial performance, based on valuable and inimitable internal resources, offers an appealing rationale for HR's strategic importance. This integration tends to focus on human capital, or employee-level attributes, and the RBV's emphasis on recognizing existing strategic resources rather than the development of those strategic assets. However, there is little evidence of the impact of this theoretical work on the empirical SHRM literature. Instead, the most we can say is that we have a set of empirical results that are consistent with the theoretical implications of the strategy literature but do not follow from an SHRM theory that directly integrates that theoretical literature. As Barney (2001) has observed more broadly about the influence of RBV theory, the strategy literature simply provides a theoretical context for examining the implications of HR for firm performance. 
Priem and Butler's (2001) concern about the "level of abstraction" in RBV theory applies to SHRM theory as well. The link between the HR architecture and most RBV concepts remains too abstract and too indirect to guide either empirical work on the "black box" in SHRM or management practice. However, recent attention to the independent influence of "implementation" in the strategy literature offers an opportunity to make the theoretical HRfirm performance link more concrete. As Barney has noted, implementation was originally omitted from the RBV as a "theoretical convenience," under the assumption that "implementation follows, almost automatically" (2001: 53). Implementation has played a similar role in SHRM theory. Rather than considering implementation as an independent theoretical construct, SHRM theory has relied on the implication that an appropriate match between the HR architecture and strategic choice (e.g., Porter's positioning strategies like differentiation or cost leadership) results in effective implementation.

RBV theorists now recognize that "the ability to implement strategies is, by itself, a resource that can be a source of competitive advantage" (Barney, 2001: 54). Implementation should be given similar prominence in SHRM theory. The HR system-firm performance link is not as direct as suggested by the prior SHRM literature. It has long been recognized that intermediate outcomes, as part of an indirect link, are central to a more complete understanding of how the HR architecture drives firm performance (Becker \& Gerhart, 1996). The question is, What are the most important intermediate outcomes?

A new emphasis on strategy implementation in SHRM theory implies a new set of intermediate outcomes and a new locus of fit for the HR architecture. Although the SHRM literature has always acknowledged the importance of an HR-strategy fit (Schuler \& Jackson, 1987; Wright \& Snell, 1998), the nature of that fit implies a generic relationship between the HR Architecture and the larger competitive strategy. Irrespective of the strategic framework being used (Miles \& Snow, 1994; Porter, 1985), prior work typically posits three or four competitive strategies available to the firm and an appropriate HR architecture for each of these competitive strategies. For example, an HR focus on rewarding outcomes rather than procedures is suggested as an appropriate fit with a prospector (innovation) strategy (Miles \& Snow, 1994). Similarly, role behaviors that emphasized risk taking were deemed an appropriate fit with an innovation strategy (Jackson \& Schuler, 1995). Because there are only a limited number of competitive strategy types, it follows that there are a limited number of appropriate HR architectures. This notion of fit obviously limits the uniqueness of HR architectures across firms, makes them easier to imitate, and reduces their value as sources sustainable of competitive advantage. The empirical evidence seems to bear this out. Despite a general consensus that fit ought to play a central role in SHRM theory, empirical tests of this generic HR-competitive strategy contingency have provided little support for a fit hypothesis (Becker \& Huselid, 1998; Delery \& Doty, 1996; Huselid, 1995).

Despite the lack of empirical support, we agree that contingencies should continue to play a central role in SHRM theory. But those contingencies should not focus on the ultimate positioning strategy or at the level of Miles and Snow typologies. The point of alignment should be closer to the HR architecture. The challenge is to operationalize the process of strategy implementation within SHRM theory so that it can provide a useful guide to empirical work. Here we need to rely on the strategy literature but recognize that it too continues to struggle with these issues. We would echo Priem and Butler's (2001: 34) observation that 
a more careful delineation of "the specific mechanisms purported to generate competitive advantage" is required, as are more "actionable prescriptions" (2001: 31). Thomas and Tymon (1982) more generally refer to this latter characteristic as operational validity and emphasize the need to construct theories with independent variables that managers can control. The RBV literature's reliance on constructs that are difficult to operationalize in practice limits the prescriptive value of the theory for managers (Priem \& Butler, 2001) and extends to efforts to integrate RBV into SHRM theory.

With that caveat in mind, the most general answer to the question of how to operationalize strategy implementation as a key intermediate variable within SHRM theory is to focus on a firm's strategic capabilities. In the RBV literature, terms like resources and capabilities "are used interchangeably and refer to the tangible and intangible assets firms use to develop and implement their strategies" (Ray, Barney, \& Muhanna, 2004: 24). Makadok (2001), however, made the distinction that capabilities are firm-specific and embedded in the organization. More important, their purpose is to enhance the productivity of other resources and as such serve as "intermediate goods" (Amit \& Shoemaker, 1993). This intermediate role fits well within the black box between the HR architecture and firm performance.

The notion of an intermediate good also highlights the importance of "connectedness" and location of strategic capabilities within a strategy implementation system (Siggelkow, 2002). It builds on what Ray et al. described as "important common ground" between Porter's emphasis on "activities" and the RBV focus on resources and capabilities (2004: 25). Porter's (1996) concept of the strategy-activity system and Siggelkow's (2002) notion of core and elaborating organizational elements both represent a system of capabilities that implement strategy. While the SHRM literature tends to focus on Porter's notion of market positioning, emphasizing a mix of differentiation or cost-leadership, Porter argued that the underlying strategic activities that drive that position are, in fact, the essence of strategy. "Competitive strategy ... means deliberately choosing a different set of activities to deliver a unique mix of value" (1996: 64). For example, at Wal-Mart, an integrated combination of distribution, logistics, just-in-time order fulfillment, considerable focus on stocking stores differentially to meet customer needs in each area, and very close relationships with suppliers helped to create an organizational capability and first-mover advantage that is difficult for competitors to imitate. The important point is not simply that a system of internal organizational activities might have strategic value in any organization but rather that this strategic activity system has value in large part because it will differ across competitors. In other words, simply choosing a generic positioning strategy does not imply a particular strategic activity system. Similarly, choosing a generic positioning strategy does not imply a particular HR architecture.

We are not the first to argue that strategic capabilities should play a role in a more fully articulated SHRM framework. Wright et al. (2001) proposed a more comprehensive integration of RBV concepts like dynamic capabilities into SHRM theory, although the ultimate links to firm performance are not discussed. In our view, strategic capabilities can more usefully be integrated into SHRM theory if they are linked directly to strategy implementation. This will increase their operational validity and provide much clearer implications for contingencies and fit.

So how is our proposed use of the term strategic capability more concrete and operationally valid? The strategy literature has not agreed on a common terminology, but several 
recent efforts have attempted to operationalize the notion of capabilities by their relationship to concrete business processes. We think this is a productive direction for extending SHRM theory. Eisenhardt and Martin, for example, noted that capabilities "are neither vague nor tautologically defined abstractions" (2000: 1106). Instead, they are a "set of specific and identifiable processes, such as product development, strategic decision making, and alliancing." Similarly, according to Ray et al., business processes "are the way that the competitive potential of a firm's resources and capabilities are realized and deserve study in their own right" (2004: 26). They go on to argue that RBV hypotheses are often more directly, and appropriately, tested using business process effectiveness as the dependent variable rather than overall firm performance. Returning to our question posed above-Which intermediate outcomes should we use to reflect strategy implementation?-The answer is strategic business processes.

\section{A New Emphasis on Differentiation}

Following emerging trends in the strategy literature, we argue that SHRM theory should be extended to focus on effective strategy implementation as the key mediating variable between the HR architecture and firm performance. That focus on strategy implementation is operationalized and made concrete by a focus on strategic capabilities and activity systems reflected in strategic business processes. We say strategic because not all business processes will have equal value. Strategic value requires that these business processes are a source, perhaps the source, of the value customers derive from the firm's products or services. Whether this value proposition can rise to the level of sustainable competitive advantage will depend on the ease and cost of imitation by competitors. In our framework, the strategic impact of the HR architecture is directly related to the strategic value created by these business processes.

A new locus of fit goes directly to the familiar debate about best practices versus configurations or contingencies. Structurally, this discussion focuses on whether there is one "best" HR architecture that creates value for all firms, whether there are two or three appropriate architectures (configurations), or whether there are two or three with returns that vary with the larger strategic positioning strategy (contingency theories). Although we have examined these issues in our own work, this entire line of inquiry seems more driven by empirical convenience than theoretical logic. None of these perspectives is consistent with a strategic logic based on firm-specific and inimitable resources. Given the small number of potential architectures and limited number of strategic contingencies (Porter positioning strategies), these approaches are all largely variations on the best practice story. The issue is not whether contingencies should play a role in SHRM theory but rather the locus of fit and the nature of that contingency. Nevertheless, we do not believe that it is an either/or story. There is consistent empirical support (discussed in the next section) for even the simplest of these explanations. The market for these ideas is not very efficient and may reflect what Pfeffer and Sutton (2000) described as the "knowing-doing" gap. As a result, adoption apparently provides competitive advantage, even if it is not sustainable. What is missing is a more theoretically appropriate test of the contingency story. 
This current approach to theorizing about and measuring fit implies very little variation or differentiation of the HR architecture, either between firms or within firms. By contrast, our theoretical focus on the capabilities and activity systems that are the foundation of strategic business processes implies a great deal more differentiation between firms. For example, two firms with the same positioning strategy may well be in different industries and rely on dramatically different capabilities to create value for their customers (e.g., alliancing, Gulati, 1998; forecasting, Makadok \& Walker, 2000; client services, Ethiraj, Kale, Krishnan, \& Singh, 2005). The cross-sectional variation here is not a question of high-performance versus low-performance HR systems but rather a question of which high-performance system is appropriate. Unique and firm-specific HR architectures that contribute to unique and inimitable strategic capabilities will contribute to sustainable competitive advantage. But even HR architectures that are fitted to strategic business processes common among all close competitors should create more near-term competitive advantage than more generic best practice architectures, or two or three variations fitted to the larger positioning strategy.

If the HR architecture is fitted to the strategic business process, rather than the more generic positioning strategy, it also follows that there will be a need for greater differentiation of HR architecture(s) within the firm. Lepak and Snell $(1999,2002)$ have led the call for greater theoretical and empirical attention to differentiating the HR architecture, a direction we strongly endorse. They note that the SHRM literature has tended to emphasize a "holistic" view of human capital and "the extent to which a set of practices is used across employees of a firm as well as the consistency of these practices across the firm" (1999: 32). Their key insight is that not all employees, or employee skills, are inherently strategic, and employees with different roles in the value creation process ought to be managed differently.

For Lepak and Snell, the basis for differentiating a firm's HR architecture is the value and uniqueness of an employee's skill. In effect, they develop four separate HR architectures that vary by HR system, employment relationship and employment mode. Depending on their mix of skill value and uniqueness, employee groups would be managed with one of four appropriate architectures (quadrants). It is a heavily bottom-up story. In describing their logic for including certain employees in their Quadrant 1 (knowledge-based employment), Lepak and Snell argued that "because of their value, these employees are able to contribute to a firm's strategic objectives" (2002: 520). For us, the relationship is more top-down. We would say, "When employees are able to contribute to a firm's strategic objectives, they have (strategic) value." In other words, human capital is only strategically important if it directly implements the firm's strategy. Presumably not all strategic processes will be highly dependent on human capital. As that dependency increases, employee performance behaviors in that business process are increasingly a complement to effective strategy implementation. As the elements of the HR architecture within the domain of that business process are uniquely fitted (differentiated) to produce those behaviors, the HR architecture itself increasingly becomes a strategic asset.

We also believe that the point of fit, and therefore the locus of differentiation, is the job, not the employee. A focus on jobs is an effort to consider both the supply and demand side of human capital. In other words, the value of employee skills within a firm is not just a supply side phenomenon. It is a function of how those skills are used and where they are used. The value of a strategic job is derived from the value of a strategic business process and 
could easily extend to hourly workers and manual trades (Teece, Pisano, \& Shuen, 1997). Just as in real estate, what is important about the job is location, location, location. Jobs located in strategic business processes have more value than jobs located in other areas of the business, even if they have the same job title. A computer programming job located in a strategic software development process has more value than the same job in a support function. The uniqueness of the skills required for that job is a secondary issue. The HR architecture should focus on the jobs in a strategic business process. The hiring and development practices may well vary across jobs in a strategic business process depending on how firmspecific the skill requirements might be.

It is not, however, just a question of identifying strategic and nonstrategic jobs. It is equally important to recognize that the HR architecture might have to be differentiated across different strategic capabilities within the same firm. Porter observed that "strategic positioning means performing different activities from rivals or performing similar activities in different ways" (1996: 62). This puts considerable emphasis on the strategic value of differentiation rather than best practices and universalistic approaches to HR strategy. As a corollary, it puts a different emphasis on the nature of HR's contingency with strategy. Zajac, Kraatz, and Bresser, in their review of the role of contingency theories in the strategy literature, conclude that more attention should be given to the "uniqueness of strategic fit for a particular organization at a particular point in time" (2000: 450). We believe that future theoretical work in SHRM should follow a similar direction.

This new direction reflects an evolution in our own thinking during the past decade. Although our earlier work (Becker \& Huselid, 1998; Huselid, 1995) tested for the firm-level impact of internal and external fit, the empirical results were much more consistent with a "best practice" story. Despite our call here for increasing levels of focus and differentiation in workforce investments, we continue to believe that many firms will benefit from the adoption of high-performance work system "best practices." How is this possible? In both our survey data and fieldwork, we have consistently found that the degree to which firms effectively manage even the "HR basics" varies substantially across organizations. As a result, the variance in workforce management "quality" across firms is quite large. Indeed, we would hypothesize that the existence of this variance is in part the reason why we see such robust HR-firm performance effects. The economic returns to product quality have dissipated over time as they have been factor price equalized. Similarly, if most firms did an excellent job managing their workforces, the impact on firm performance would likely be much smaller. Strategic HR gains will be much harder to capture when (or if) the HRM market approaches equilibrium. Whether this market failure is due to a lack of knowledge, a lack of managerial competence, or an inability to execute (or more likely some combination) is open for conjecture and, it is hoped, future research. However, our main conclusion is that the real strategic opportunity for most firms during the next decade requires a greater emphasis on contingencies and differentiation. Again, it is not a question of either/or but a question of the appropriate balance.

This perspective is summarized in Figure 1. The framework begins with a common set of positioning strategies but implements those strategies with a system of an interrelated business process that have a significant firm-specific dimension. The core elements in a set of strategic business processes (e.g., Process A, Process B) have both a core and differentiated 


\section{Figure 1 \\ Differentiating the HR Architecture Contingent on Strategic Business Practices}

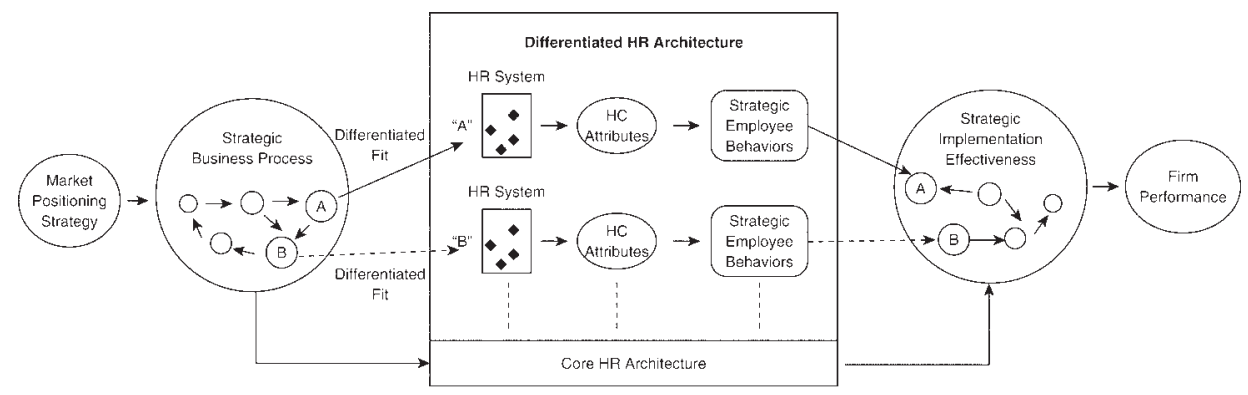

fit to the HR architecture. The core or best practice fit is that part of the HR architecture that has equal value in all strategic business processes. The differentiated fit is that part of the overall HR architecture that is structured to provide the unique human requirements of a specific business process. For example, HR Architecture A is fit to strategic Process A and differs significantly from HR Architecture B. In each case, these unique architectures provide the human capital attributes (competencies, commitment, or motivation) and employee performance behaviors required in the strategic jobs in a particular business practice. Effective strategy implementation is then a function of both core and differentiated fit.

\section{Empirical Work Going Forward}

\section{The Focus on "Managerial Significance"}

Before turning to a more focused discussion of several empirical issues, it is important to highlight an important feature of SHRM research. Unlike much of organizational research, the dependent variables in SHRM typically have obvious and direct managerial relevance (e.g., shareholder value, return on assets, labor productivity). SHRM effects can be expressed in units that are managerially significant, and this has a direct bearing on the influence of this literature.

Ferraro, Pfeffer, and Sutton (2005) and Bazerman (2005) have recently debated why economic research is more influential than the work of other social scientists. We agree with Bazerman that noneconomists are influential when they, too, make "novel prescriptions that are relevant to the marketplace" by focusing their research on "economic outcome variables" (p. 27). This observation is particularly applicable to SHRM research. For example, on the basis of the results of five national surveys between 1991 and 2000 and data collected from 
more than 3,200 firms, we have estimated that "the effect of a one standard deviation change in the HR system is 10-20\% of a firm's market value" (Huselid \& Becker, 2000: 851). More broadly, in a meta-analysis of 92 recent studies on the HR-firm performance relationship, Combs, Ketchen, Hall, and Liu, 2006) found that an increase of one standard deviation in the use of high-performance work systems is associated with a $4.6 \%$ increase in return on assets (ROA). The interest in SHRM, particularly among managers, is at least as much about the dependent variable as the independent variable. HR has become an answer to a very important question, How can we improve a firm's financial performance?

Focusing on managerial significance in SHRM empirical work also serves to strengthen the validity of those results. First, financial effects such as an x percentage change in shareholder value or $y$ percentage change in ROA provide a compelling external validation to results that otherwise are simply "statistically significant." The larger business and strategy literature offers reasonable boundaries for the effects of a wide range of managerial innovations. The validity of SHRM empirical results should be interpreted within this context. Studies that imply $70 \%$ to $80 \%$ increases in firm financial performance metrics based on reasonable changes in one or two HR practices can be questioned as theoretically and empirically implausible. Second, an empirical literature that focuses on managerially relevant effects provides an important point of comparison for future work. Going forward, empirical work should be located within a cumulative body of effect sizes. This will not only serve to validate these new results but also clearly highlight their contribution well.

\section{Specific Empirical Issues}

Empirical SHRM research has been an exciting line of inquiry for more than a decade, and it is not our purpose to provide a comprehensive review of that literature. Instead, this section will focus on two objectives. First, we will examine several of the empirical challenges that would follow from a theoretical emphasis on strategy implementation and differentiation of the HR architecture. Second, we revisit several methodological challenges that continue to confront this literature and suggest where further work is required.

A new focus on intermediate outcomes and strategy implementation. The strategy literature focuses on sustained competitive advantage as the basis for above-average firm performance. This requires an equivalent emphasis on higher order measures of firm performance in SHRM research. Nevertheless, one of the implications of our proposed theoretical focus on strategy implementation is that empirical SHRM research can be refocused on key intermediate outcomes. By locating effective strategy implementation as an explicit intervening variable in SHRM theory, strategically focused empirical research does not necessarily require firm financial performance as the dependent variable. Empirical work in SHRM should be extended to include a focus on measures of effective strategy implementation. Particular attention should be given to those strategic business processes that have high human capital content. However, it is essential that these measures have a theoretically clear line of sight to the ultimate strategic (financial) outcomes. In order for SHRM "effects" to be strategically significant, the dependent variable must have a clear strategic significance. 
A new focus on intermediate outcomes poses several challenges. Most important, it means that intermediate outcome measures will have to be "strategically validated" demonstrating their importance to effective strategy implementation in a particular sample of firms. The challenge will be to develop research designs that reflect the firm-specific and idiosyncratic character of these intermediate outcomes. The elements of a firm's strategic business processes with the most strategic value are likely to vary across firms and across strategies, making large-scale multi-industry studies more difficult. Although there may be a "best practice" dimension to some of these business practices (Eisenhardt \& Martin, 2000), particularly among close competitors, SHRM researchers need to be equally attentive to their firm-specific characteristics. In either case, the design of empirical work that focuses on strategic business processes must carefully establish that the particular process is indeed strategically significant to the organizations in the sample. Even such processes like customer service that have widespread appeal may not always be strategically important. Porter (1996), for example, described strategic activity systems from three disparate industries (airlines, retail furniture, and financial services), and "limited" customer service is a dimension of effective strategy implementation in two of the three companies.

Our call for increased focus on intermediate outcomes should not be interpreted as encouraging a greater use of unit-level and plant-level financial performance as the solution. Intermediate financial measures do not measure the strategy implementation process or illuminate the "black box" in SHRM. Intermediate financial outcomes would only be appropriate dependent measures when testing an empirical model in which the strategic business process or another element of strategy implementation mediates the relation between HR and the financial outcome (e.g., Skaggs \& Youndt, 2004).

Indeed, future SHRM empirical work may benefit from a return to more narrowly drawn industry studies like MacDuffie (1995). However, instead of focusing on production units and operational performance, the focus should be on strategic business processes. A good example of research that moves us in this direction is the recent work by Collins and Smith (2006). Here the authors limit their analysis to high-tech firms and focus on the impact of the HR architecture on knowledge exchange capabilities. There is a well-developed theoretical rationale for HR's influence on knowledge exchange as well as a clear rationale for the strategic importance of knowledge exchange in a high-tech firm. Similarly, Skaggs and Youndt (2004) developed a theoretical rationale for differentiating the service production process and the appropriate HR architecture within a narrow industry sector as the basis for their empirical hypotheses. Likewise, the strategy literature has routinely relied on in-depth "context-specific" analyses (Ethiraj et al., 2005; Makadok \& Walker, 2000; Raff, 2000) to study the evolution and impact of strategic capabilities.

A new focus on fit and contingencies. Our proposal to refocus SHRM theory on strategy implementation, and by implication strategic business processes, also suggests both a new emphasis and a new focus for fit in the empirical SHRM literature. If these strategic business processes or their underlying activity systems are differentiated across firms and within firms, then HR architectures should be equally differentiated. The nature and appropriate level of this HR differentiation is an empirical question and one that bears directly on the role of contingencies and fit in SHRM. Incorporating an increased level of differentiation into SHRM will require new direct measures of 
fit and much less reliance on the more familiar moderator variable approach. The moderator variable approach has an appeal if one is testing whether the effect of a "best practice" HR system varies over a small set of strategic positioning strategies. By contrast, we argue that the value of the HR architecture is in large part determined by the fit between the HR architecture and a largely idiosyncratic business process. In a broad cross-sectional sample, there is neither a "best" HR architecture nor a small set of strategic moderators.

Locating strategy implementation as the locus of fit has direct implications for notions of external and internal fit. Internal or horizontal fit (among the elements of the HR architecture) and external fit or vertical fit (between the HR architecture and a strategic business process) are no longer independent constructs. First, internal fit should have no value in the absence of external fit. A highly integrated, mutual reinforcing system of HR practices, all of which do little to improve strategy execution, will have little strategic value. Second, if the HR architecture, and by definition this means the elements within that architecture, is focused on executing the strategic business process, the architecture will necessarily have internal fit.

An emphasis on principles? Colbert (2004: 345) has recently revisited the distinction between principles, policies, and practices in SHRM (Becker \& Gerhart 1996; Schuler, 1992) and argues that from a systems perspective, it is the principles of the HR system that are the central points of managerial leverage. He gives as an example that "employee participation in all aspects of the business is critical in our success." Once the principles are established, policies and practices "will self organize, which can mean that they flow in concert with the particular idiosyncratic context of the firm" (Colbert, 2004: 351).

Empirical work focusing on strategy implementation and the necessary fit between the HR architecture and strategy business processes might also benefit from an emphasis on SHRM's organizing principles as an initial point of departure. An example of several principles that might be explored empirically include the following:

- The HR architecture should focus on strategy implementation rather than strategic positioning

- Differentiate the HR architecture as required by key business processes

- Disproportionately invest in employee performance in strategic jobs

It is important to point out that although these principles represent an increase in the level of abstraction above policies and practices, they should not devolve into the conceptual murkiness for which RBV theory has been criticized. They need to retain their operational validity. Ericksen and Dyer's (2004) work on strategic HR in high-reliability organizations is a good example. To the extent that SHRM empirical work focuses on principles, the hypotheses necessarily move in the direction of "best practices." This, in turn, will allow for more conventional fit analysis using moderators rather than the direct measures of fit described above.

The prescriptive challenge. Finally, we should highlight an important caveat to a more prominent role for contingencies in empirical SHRM research. Zajac et al. (2000: 429) noted that although fit "is one of the most widely shared and enduring assumptions" in the strategy literature, there has been very little research on the subject, either empirically or theoretically, 
in recent years. Among the reasons they give for this declining attention to fit is the nature of the concept. It is inherently multidimensional and not easily captured by simple bivariate statements. Introducing increasingly differentiated HR architectures and strategic business process in SHRM, as we have proposed, reflects that multidimensional challenge. Zajac et al., however, made a more fundamental point that bears directly on the nature of SHRM research. They also observed that fit requires scholars to make normative statements about what organizations should do rather than descriptive statements about what they did do (p. 430). Indeed, to the extent that SHRM theory emphasizes organizational relationships (like fit and alignment) linking HR to other organizational processes within the HR-firm performance "black box," HR scholars have likely moved beyond the current experience of most organizations.

We are prescribing how firms ought to structure their HR architecture, not necessarily describing how they currently structure their HR architecture. Typical cross-sectional studies implicitly assume that some firms will structure their HR architectures more "appropriately" than other firms and that those differences will be reflected in improved firm performance, other things equal. Perhaps those firms with high values on the HR measure have knowingly chosen such policies, or maybe they just got lucky, but the empirical analysis will reveal what may be a heretofore unrealized effect. Estimating these effects and testing these hypotheses is much more difficult when most firms have yet to implement the more prescriptive recommendations. For some hypotheses, this may require a move away from large sample survey research and more emphasis on case studies and small "experiments" with cutting edge organizations.

\section{Considering Alternative Explanations}

Finally, any analysis of a literature based largely on field research raises the question of how well that literature has ruled out alternative explanations. The SHRM empirical literature has mushroomed in recent years, and there is consistent evidence that high-performance HR systems, broadly defined, have positive effects on firm performance that are both statistically and managerially significant (Combs et al., 2006). These results are increasingly refined as studies report results with effects on financial performance expressed in financial magnitudes with clear managerial implications. Despite this progress, it is appropriate to assess how well this literature has addressed three key methodological challenges that would call these results into question: omitted variable bias, measurement error, and mutual causation or simultaneity.

Before considering these issues, however, it is important to make an observation about the point of comparison. In other words, alternative compared to what? ${ }^{1}$ The most common alternative explanation in the managerial literature tends to be "no effect." The question is whether we are observing an effect, in the case of the SHRM literature a positive relationship between HR and firm performance, when, in fact, there is no true relationship. This is, however, a relatively blunt standard. Literatures like economics, for example, are much more likely to focus on degrees of estimation bias. Empirical labor economics might focus on whether the rate of return on education is $\mathrm{x} \%$ or $\mathrm{y} \%$, or whether the union effect on wages is overstated or understated in prior work. Those literatures have evolved to the point where 
the empirical interest is not so much in demonstrating that there is a nonzero effect but rather carefully estimating the magnitude of that effect. One reason for this is that effects matter because they are expressed in economically meaningful units. This, of course, highlights our earlier point about the significance of the dependent variable in SHRM research. We are in a position to develop a meaningful conversation about the size of HR's effect, and the magnitude of potential biases in those estimates, rather than simply focusing on whether the effects exist at all.

Omitted variable bias. Empirical relationships in the SHRM literature typically take the form of regression models with a measure of organizational performance modeled as a function of the HR architecture and various control variables. Omitted variable bias occurs if an omitted variable is correlated with both the HR variable and the dependent variable. The direction and magnitude of that bias will depend on the direction and magnitude of those correlations. There are two ways in which commonly used estimation models in the empirical SHRM literature might raise questions about omitted variables. The first follows from our earlier discussion of the importance of the dependent variable as the source of SHRM's influence. Dependent variables like productivity (revenue per employee), ROA, or a shareholder value measure all have enormous theoretical and empirical literatures associated with them. There are well-developed estimation models in those literatures that typically extend beyond one or two independent variables. It is important that empirical SHRM research reflect the richness of these models. Otherwise, our literature is open to questions about whether the effects of the HR variables are also reflecting the effects of variables that have been omitted from the conventional estimation model for that particular dependent variable. At a minimum, if those additional variables have been omitted from the model, authors ought to explain why this omission is not a significant threat to the validity of their results.

A more fully specified estimation model based on the prior empirical literature for a particular dependent variable is a reasonably tractable problem. The measures are generally available in the same data sets as the dependent variable. A more challenging problem involves omitted variables that reflect other management policies that also influence firm performance. For example, are firms that have outstanding marketing strategies or excel at supply chain management also more likely to have high-performance HR systems? We examined this alternative explanation in an earlier analysis (Huselid \& Becker, 1997). Using a simple rating of the quality of "other" management functions in the firm relative to close competitors as our measure, the effect of the high-performance work system (HPWS) measure was virtually unchanged when the "other management" variable was included in the model. Of course, if such value-creating policies do coexist with the presence of a HPWS, it may well mean that those effects are overstated in their respective literatures, and it is HR that deserves more credit. The success of these other policies, like marketing or supply chain management, may in large part be due to the employee performance in those functions, which is the result of the firm's high-performance HR system.

In addition, there are a wide range of "people"-oriented practices, like leadership, that we would normally consider as positive influences on firm performance yet may also be positively correlated with the presence of a HPWS. One approach to the problem is to argue that control variables capture these other effects, but we would have to believe the mechanism by which 
these other variables affect performance is considerably different from the way in which HR affects performance. Otherwise, we would be "controlling" for the HR effects as well. The value of such controls seems more plausible for the non-people-oriented policies.

Although this issue continues to be a challenge for the empirical SHRM literature, particularly the multi-industry cross-sectional studies, there is no easy solution. Certainly, we recommend that future work at least attempt to address this issue with some additional measures of these other policies. Again, we do not expect these studies to find that HR has no effect but rather continue to provide a greater precision to the growing body of point estimates. Future research may benefit from more attention to small quasi-experimental studies that follow the introduction of SHRM changes, particularly if they focus on the type of differentiated fit we discussed above. This approach would have the potential to control for other policies that might be held constant over the introduction of the HR changes.

Measurement error bias. In recent years, the role of measurement error in the HR measures has been a subject of some interest in the empirical SHRM literature. Gerhart, Wright, McMahan, and Snell (2000) contended that SHRM effects based on single respondent surveys were significantly undermined by the presence of measurement error in the SHRM measures. We have argued (Huselid \& Becker, 2000) that where single respondents were key informants and HR practice measures focused on more objective attributes (like hours of training), the effects reported in large-scale multi-industry samples such as our own work were not significantly influenced by the issues raised by Gerhart et al. (2000). Furthermore, it was our view that if this issue was to be considered a serious challenge to the growing empirical literature, the magnitude of the problem could only be evaluated within the context of samples similar to our own work rather than in the small sample of very large organizations used in Gerhart et al. (2000). Absent this kind of compelling evidence, a general expectation of a multirespondent design for work in SHRM would essentially render largescale studies infeasible.

During the past 5 years, there have indeed been a number of SHRM studies using multirespondent designs in national multi-industry samples. Notably, several have been conducted by the coauthors (Wright and Snell) of the Gerhart et al. (2000) article. Each of these studies reveals a similar pattern. Beginning with a large national sampling frame, the authors attempt to collect data from multiple respondents, the response rate is trivial, and the interrater reliability using the very small sample of firms with multiple respondents is quite high. Finally, the analysis is ultimately based on the only feasible sample - single respondent measures.

In an early effort to collect multirater measures, Lepak and Snell surveyed 2,375 firms but were forced to rely on just "23 firms in which identical surveys were completed" (2002: 529) as the basis for their reliability calculations. Not surprisingly, the study's analysis was not based on the multirespondent sample. Later, Youndt and Snell (2004) surveyed 919 firms and attempted to collect responses from both the CEO and VP for HR. The response rate was somewhat higher than in Lepak and Snell (2002) but still yielded just 71 observations. Although Youndt and Snell ultimately merged both single and multiple respondent firms, their analysis of the multirespondent reliabilities indicated that because "multiple top level executives from the same firm provided very similar responses, there is evidence to suggest that whether we had responses from one or numerous executives from each firm our results 
would be similar." Most recently, an article coauthored by Pat Wright (Datta, Guthrie, \& Wright, 2005) reports a multirespondent sample of just 33 firms (p. 143) out of a sampling frame of 971 manufacturing firms. The authors conclude with some understatement that indeed when it comes to multiple respondent surveys, "a high response rate in multi-industry research designs may prove challenging" (Datta et al., 2005: 143). More to the issue of whether prior empirical results should be called into question, the results of this study, which relied in part on the HR index measures developed in Huselid (1995), reported effects on labor productivity (the only dependent variable) well within the same range reported previously in Huselid (1995) and Becker and Huselid (1998).

So where does this leave us? It is important that these and other studies have explored the implications of single rater surveys using multi-industry samples similar to those that had been called into question by Gerhart et al. (2000). However, even as the work of several of the original authors of the Gerhart et al. (2000) article has demonstrated, there is nothing in these subsequent studies that casts significant doubt on the earlier single-respondent-based results. With the challenges of large-scale survey research in this area increasingly daunting, we believe that the wisest use of scarce research resources should be devoted to increasing overall response rates among well-crafted single-respondent surveys. There seems to be little incremental contribution to continuing to divert those resources to largely futile (and apparently unnecessary) efforts to develop multirespondent samples.

Mutual causation and simultaneity. A common concern expressed in the empirical literature is the caveat that the positive cross-sectional HR-firm performance relationship is, in part, influenced by mutual causation, or simultaneity bias. Unfortunately, this issue tends to typically receive a perfunctory mention in the Limitations section of most empirical articles and is rarely addressed directly. Notable exceptions are recent articles by Guest, Michie, Conway, and Sheehan (2003) and Wright, Gardner, Moynihan, and Allen (2005).

On this issue, it is probably useful to recall Fisher's dictum. R. A. Fisher, the eminent statistician, was reportedly once asked for his advice about how to move from association to causation, and his recommendation was simple: "Make your theories more elaborate" (Cox, 1992: 292). Indeed, the saliency of this issue in the SHRM literature is directly related to the "black box" between the HR architecture and firm performance. Going forward, focusing on the link between the HR architecture and strategy implementation provides a clearer strategic rationale for HR's ultimate impact on firm performance. More important, it suggests little theoretical rationale for reverse causation.

Unfortunately, the prior SHRM literature lacks the kind of well-developed theoretical framework that would inform a well-specified empirical model on this issue. The initial logic tends to posit mutual positive effects, or at least a positive effect from firm performance to the HR system. But why do we necessarily assume that high-performance HR systems require significantly more financial resources? SHRM is more about how the firm's resources are spent and the focus of the HR system than about the level of spending on HR. The positive firm performance-HR story also seems to suggest that the discipline and acumen that otherwise produced outstanding financial results are missing as these companies throw money at an HR fad. It may be the case that the same business acumen and discipline that creates success in the rest of the business is also more likely to recognize the wisdom of an SHRM 
approach. This explanation, however, is closer to the "other management" bias described earlier. Indeed, one could just as easily argue that, in fact, it is not the more successful firms that adopt these systems; instead, it is the struggling firms who turn to their HR systems as an opportunity to improve performance. This, of course, would still be reflected in mutual causation in a cross-sectional sample, although a single equation model with HR as the independent variable would tend to understate HR's true effect.

Assume that we develop a theoretical logic that firm financial performance affects the HR system. How should these expectations be incorporated into empirical work? One approach might be to locate natural experiments where HR changes are measured and subsequent changes in financial performance observed for otherwise similar organizations or even organizational units. This type of result would give us some evidence that HR's effect on financial performance could be "real." Once a series of such studies accumulated, they would in the aggregate provide a compelling test of this alternative hypothesis.

An alternative approach is to improve our estimation models when analyzing the more common large-scale cross-sectional data sets. The problem is any mechanism that gives rise to HR and firm performance being jointly determined will be very difficult to model. We are not likely to know when an HR change was implemented or how much time is required before any effects will have been realized (Guest et al., 2003). Recent work by both Wright et al. (2005) and Guest et al. (2003) rely on analyses of HR measures at Time T and measures of firm performance at Time $\mathrm{T}+1$ and $\mathrm{T}-1$. They argue that the absence of an HR effect on Performance at $\mathrm{T}+1$, controlling for Performance at $\mathrm{T}-1$, calls into question any interpretation that HR's effect in prior cross-sectional research is a causal relationship. Guest et al., however, correctly observed that this approach is really a "test for the impact of HR practices on change in performance" (2003: 297). This, of course, is a very conservative test of HR's effect on performance. There is no reason to believe that in any sample of HR and firm performance at Time T, HR's unrealized effect is all that significant. Indeed, the strategy literature focuses on cross-sectional heterogeneity in firm performance, and strategies will be successful when they result in sustainable competitive advantage. HR's contribution to competitive advantage is much more likely to be reflected in differences in the levels of profitability than in rates of change.

Wright et al. (2005) recognized this issue and pointed out that a "dual causation" model might well explain their results. We agree. Unfortunately, Wright et al.'s observation that "the observed payoff [of HR practices] may be far less than the estimates provided in past research" (2005: 433) is simply not informed by their analysis. The single equation results could be overstated, or understated, by a lot or little. The dual-causation hypothesis requires empirical testing, and we are aware of only one paper (Huselid, 1995) that tested these effects in a simultaneous equation system. In that study, the HR effects were slightly more positive in the multiple equation estimates (p. 666).

Where does this leave us? We agree with both Guest et al. (2003) and Wright et al. (2005) that the issue of simultaneity bias should be more systematically considered in the empirical SHRM literature, although it does not strike us as the most compelling alternative explanation to the extant literature. Having said that, the literature would benefit from a comprehensive treatment of the dual-causation thesis where the estimates are based on a simultaneous equation system and drawn from the kinds of multi-industry samples that have been called into 
question. Guest et al. (2003) and Wright et al. (2005) raised the right question, but the empirical tests do not correspond to the complexity of the problem. Aside from the reliance on preand postperformance measures to capture dual causation, Wright et al. (2005) limited their analysis to simple and partial correlations. Although their reliance on data from a single firm arguably should reduce the variance in the firm performance measures, the simple correlation between HR practices and profitability never explains more than $10 \%$ of the variance in their profitability measure (Table 4, p. 429). Surely this residual variance is attributable to something other than measurement error in the dependent variable. The most likely explanation is the systematic influence of other differences among these units, differences that may also be correlated with the level of HR practices. Once again, this is a literature where the effects matter, and those effects presume a reasonable set of control variables to rule out the most basic alternative explanations. ${ }^{2}$

We would also make what is perhaps a philosophical observation about how these types of methodological issues are best examined. Guest et al. (2003), for example, examines the causality question within a large-scale multi-industry analysis of UK data. The sample and context are equivalent to the types of prior U.S. studies where causality has been called into question. We have adopted a similar approach in our own work (Becker \& Huselid, 1998; Huselid, 1995; Huselid \& Becker, 1997). Following Gerhart et al. (2000), Wright et al. (2005) distinguish between studies that examine methodological as opposed to theoretical issues.

We have argued that such narrowly drawn methodological articles, typically based on just a handful of firms, or even multiple units in the same firm, simply raise more questions than they answer (Huselid \& Becker, 2000). Moreover, it seems unnecessary. Just as the authors in Gerhart et al. (2000) could have reanalyzed their own data to examine these questions, Wright recently coauthored an article (Datta et al., 2005) that could have easily included pre- and postperformance measures as part of the analysis. Instead, there is simply the acknowledgment that "it is also possible that firms experiencing higher productivity are better positioned to invest in high performance practices" (Data et al., 2005: 143). Unfortunately, there is no indication of when these productivity measures were collected, so the reader can only speculate how the results fit into the kinds of criticisms raised in Wright et al. (2005).

\section{An Agenda for Future Research}

A clearer articulation of the "black box" between HR and firm performance is the most pressing theoretical and empirical challenge in the SHRM literature. This requires a new emphasis on integrating strategy implementation as the central mediating variable in the HRfirm performance relationship. It goes to the core of what makes SHRM strategic, and not simply a traditional HR perspective with a new set of dependent variables. There are also direct implications for the nature of fit and contingencies in SHRM. It highlights the significance of a differentiated HR architecture not just across firms but also within firms.

Moving the literature in this new direction suggests a rich and varied research agenda, both theoretically and empirically. Several of these new directions were discussed above. However, there are a number of related questions that also need to be considered. 


\section{Articulating the Limits of HR's Strategic Impact}

Given SHRM's strategic focus, a core question is always how HR influences firm performance. Porter (1996), however, distinguishes between managerial decisions that create competitive advantage and those that simply improve operational excellence. Going forward, we need more work delineating the theoretical and empirical limits of HR's strategic impact. For example, does slow and imperfect diffusion of SHRM ideas among HR professionals result in significant financial gains from HR's improved operational excellence? How does this market failure explanation square with the highly successful "diffusion industry" of conferences and workshops that purport to share "best practices"?

Given a new focus on strategy implementation, under what conditions will the impact of the HR architecture move along the continuum from operational efficiency to sustained competitive advantage? Will that effect vary with product market dynamism and product life cycles? Are there some capabilities and perhaps some industry segments where HR's strategic impact is likely to be inconsequential? Empirical work that examines the relationship between several easily copied or "best" HR practices and measures of financial performance needs to consider why those practices are strategic and not simply better HR.

Our own work (Becker \& Huselid, 1998; Huselid, 1995) emphasizes HR systems that are not so easily imitated, and we can demonstrate meaningful effects on multiple measures of firm performance over multiple national samples. Nevertheless, we cannot rule out the possibility that much of those effects represent improved operational excellence rather than a sustainable competitive advantage. This distinction continues to challenge empirical work in the strategy literature as well. The difference between the two literatures is largely one of recognition. Strategy researchers are more aware of the problem.

\section{The Limits of Differentiation}

We have argued for a much greater focus on differentiation in the HR architecture, both between firms and within firms. But this should not be interpreted as another variation of the debate over universal versus contingent HR systems. That distinction is too narrow, emphasizing the contingency with a small set of positioning strategies. When contingencies are instead focused on the processes that implement a strategy, the appropriate question is not best practice versus contingencies. The interesting question will focus on the appropriate mix between core and differentiated HR practices, and whether certain practices are more easily differentiated. What features of the strategic or organizational environment will determine the appropriate mix of differentiation and best practices for a particular firm? Likewise, are there particular functions within the HR architecture that are more appropriately offered as a best practice, whereas others are more likely candidates for differentiation?

A greater emphasis on differentiation within the firm means that fit will play a much more central role in SHRM theory. Does this approach necessarily create a tension between the benefits of fit and the constraints on flexibility (Wright \& Snell, 1998)? In particular, what are the limits imposed by dynamic market environments, and would those apply to all strategic business processes in the organization? It is not just that greater fit might come at some 
cost in terms of flexibility. What is the relative magnitude of those costs and benefits, both theoretically and empirically?

Perhaps more important is the issue of differentiation among firms. The extant SHRM literature suggests very little differentiation. If strategy implementation is the core value creation mechanism for SHRM, what is the optimal mix of differentiation among HR architectures of close competitors? Building competitive advantage around strategic capabilities requires a degree of differentiation in those capabilities across close competitors. Eisenhardt and Martin (2000) found that strategic business processes often approach best practices among close competitors, although they may be executed differently. SHRM empirical work would benefit from a similar analysis of HR architectures within the context of close competitors. Specifically, do HR architectures that are differentiated across similar business processes provide significant improvements in the execution of those strategic business processes among close competitors? Do HR architectures that appear to be best practices in large multi-industry studies in fact reveal meaningful differentiation when analyzed within the impact on strategic business processes among close competitors?

\section{A New Emphasis on Strategic Jobs}

We argue that HR's strategic impact is contingent on its contribution to the effectiveness of strategic business processes. The value of this impact increases as the HR architecture is differentiated by strategic business processes. We posit that this impact works disproportionately through "A" or strategic jobs in those business processes (Huselid, Beatty, \& Becker, 2005). This implies that some jobs are strategic (and more valuable) and others are not. The construct of the strategic job needs to be more fully articulated. Why are some jobs in a strategic business process disproportionately valuable? What determines that difference in value? In particular, what are the boundary conditions for this construct? How do we reconcile the notion of strategic jobs with potential interdependencies among jobs? There seems to be a particularly interesting opportunity to explore the concept of the strategic job from a network perspective. Strategic jobs are consistent with a hub-and-spoke network. But are some strategies more effectively implemented with decentralized networks, where there is no obvious strategic job?

Introducing strategic jobs as a key construct in SHRM will require a wide range of new empirical work as well. There are at least two fundamental questions that need to be explored. The first is whether, in fact, strategic jobs exist in practice. What is the evidence that a small number of jobs in an organization create a disproportionate share of the firm's strategic value? What is the magnitude of any value differential? The second question would examine the strategic impact of disproportionately investing in strategic jobs. We would expect a significantly higher return from investments in strategic jobs than from investments in nonstrategic jobs. By what mechanism and by what degree does the firm's HR architecture affect that value differential?

\section{What Is the Likely Impact on Employees of Strategic Differentiation?}

The impact of SHRM on employees, as opposed to firm performance, has been a recurring question in the literature (Osterman, 2006). A strategy of disproportionate investments 
in strategic jobs is more about a reallocation of resources within the labor force than a redistribution between the labor force and shareholders. Nevertheless, Pfeffer (2005) argued strongly in favor of HR systems that minimize status differences among employees. It is clear that a new emphasis on strategic and nonstrategic jobs would not only result in significant differences in how some employees interact with the HR architecture; also the level of investment directed to the employees in those jobs categories would be considerably different (Huselid, Beatty, \& Becker, 2005). These are important theoretical and empirical questions for SHRM. What is the impact on employees in nonstrategic jobs from disproportionate investments in strategic jobs? Where is the greater cost, among employees in strategic jobs who are currently underperforming in an undifferentiated system or among employees in nonstrategic jobs whose performance might be affected by a differentiated system?

\section{SHRM in Practice}

Any discussion of the future of SHRM needs to acknowledge the central role of management practice, both as a basis for the widespread interest in the field as well as validity check on our research agenda. If the prescriptions from the HR strategy literature prove to be either inaccessible or irrelevant to practicing managers, the vitality and prominence of the field will surely suffer. This section highlights what we consider to be the most important challenges facing organizations as they attempt to turn SHRM concepts into practice. ${ }^{3}$ Beyond providing some useful insight for practice, we hope these observations will also inform SHRM scholarship more generally as well.

\section{Workforce Strategy Rather Than HR Architecture}

The most general implementation challenge facing HR professionals reflects an interesting conundrum. We find widespread acceptance among senior HR and line managers of the notion that an appropriately designed and implemented HR strategy can make a managerially significant contribution to their firm's financial performance. Any skepticism they express generally reflects the extent to which they believe the managers in their own firms are capable of the transition. Most HR professionals, and certainly all senior HR professionals, want to play a strategic role in their organizations, if for no other reason than senior line managers increasingly demand it. Unfortunately, although SHRM theory focuses on inimitable HR systems aligned to strategic goals, HR professionals too often focus on cost control and efficiency gains in an effort to demonstrate their bottom-line success. New measures with names like "human capital value added" are sometimes used to justify traditional practices and approaches to workforce measurement (e.g., cost per employee or benefits expense as a proportion of revenue). This approach merely reinforces the view that the HR function is a cost center and does very little to improve the firm's strategy implementation.

Even in a firm where HR professionals (and line managers) understand SHRM concepts, the HR function's legacy reputation is often a significant hurdle to overcome. As one line manager put it, 'I'm absolutely convinced that doing a better job managing the workforce would create considerable wealth in our business. I'm just not convinced that anyone in the HR department can 
help us get there.” This quote highlights an important distinction between managing the workforce and managing the HR function. The notion of workforce strategy is understood by managers in much the same way as academics speak of the HR architecture, with one important difference. It highlights a shared responsibility for strategic workforce performance between line managers and HR professionals that is not as central in the HR architecture construct.

This is not just a case of putting a new title on the same story. There is a lesson here for both managers and academics. The notion of workforce strategy appears to be a much more effective organizing principle for SHRM concepts in practice because the involvement of line managers provides a much clearer line of sight to an emphasis on strategy execution. The concepts of fit and alignment in SHRM theory are more easily implemented when line managers and HR professionals focus on strategic business processes, and not individual HR practices. It helps to mitigate the all too common situation where HR professionals find the organization's strategic goals either unclear or inconsistent, making it all but impossible to determine the human capital dimension of those goals.

\section{The Challenge of Differentiation}

A related issue that poses a major departure from past practice is the increased emphasis on differentiation. There are really two dimensions of differentiation that have to be considered here. The first is more structural in terms of differentially focusing the workforce strategy on strategic versus nonstrategic jobs. HR professionals tend to associate "strategic" with practices that are firm wide and cover a broad range of employees, along the lines of a core behavioral competency. We find the acceptance of more differentiation to be directly related to the adoption of the broader approach to workforce strategy described above. It provides a clear and legitimate basis for identifying the differential value of jobs and is typically endorsed by line managers. Disproportionate investments in strategic jobs appear more compelling when the status quo is a strategy that tends to underinvest in the strategic jobs and overinvest in the nonstrategic jobs (Huselid, Beatty, \& Becker, 2005). Once the strategic rationale for this differentiation is explained to managers, they often react as if a burden has been lifted. The mantra that "employees are our most important asset" often permeates organizations, but in reality managers often interpret this to mean that they need to invest in everyone in equal measure. The notion of differential investment based on a strategic logic provides an actionable solution.

The second implication of differentiation is at the level of employee performance. This means making meaningful performance distinctions among employees, particularly in strategic jobs. These distinctions will mean greater, not less, variation in rewards and greater efforts to exit those employees who do not meet the organization's performance standards. Implementing this increased differentiation again reflects the increased role of line managers. Designing an HR system with greater differentiation is not the problem. The challenge is motivating line managers to implement these systems. Not surprisingly, motivating the line managers requires that they be held accountable for the results of the workforce strategy and the extent to which they manage talent effectively. Again, this suggests that future SHRM research should incorporate a wider notion of the HR architecture and in particular the role of line managers in implementing a workforce strategy. 


\section{The Measurement Challenge}

HR professionals face an additional challenge, or what some may call a motivation, when attempting to adopt differentiated workforce strategies. We alluded earlier to the pressure to measure HR's performance in a way that demonstrates its strategic contribution. Citing the broad academic evidence of HR's strategic impact only goes so far. Too often senior HR leaders are reduced to presenting results from the latest employee survey, or trends for various turnover rates. When the CEO asks, "Why is this important?," they have no good answer. A solution to this problem requires a distinction between the human capital dimension of strategy implementation (SHRM's focus) and the HR function. Traditional HR measures (like cost per hire) focus on the performance of the HR function and tend to rely on external benchmarks. This not only limits consideration of HR's performance in terms of administrative efficiency but implicitly treats strategies as commodities with appropriate market benchmarks. A key point that we made in The Workforce Scorecard was that most organizations have much better accountability and control systems for raw materials (roughly 15\% of total expenses) than they do the workforce (65\% of total expenses). As a result, a hospital can pinpoint the source of a defective bandage, or a manufacturing firm can identify the supplier of a bad bearing with a high degree of accuracy and speed. However, most firms have no clue as to the source or reason for their defective (or high-quality) managers, if, in fact, they even know who they are. For firms to effectively execute business strategy, they must develop a much better understanding of the causes and consequences of workforce performance. They must also do a much better job of holding line managers accountable for the most expensive resource that has been assigned to them.

Measures are answers to questions, and most benchmarking measures do not answer a strategic HR question for an organization. By contrast, the intermediate measures implied by our emphasis on strategy implementation put more emphasis on results that appropriately capture HR's strategic contribution (Becker, Huselid, \& Ulrich, 2001; Huselid, Becker, \& Beatty, 2005). While not traditionally part of HR's measurement system, HR professionals recognize the value of such measures because line managers value them as well. The measurement of intangibles is a developing area in management and one that is particularly applicable to the field of SHRM (Ittner \& Larker, 2003).

\section{New Competencies in Workforce Management}

What it means for HR leaders to play a strategic role in their firms role has changed considerably, especially during the past 5 years. Senior managers continue to struggle with how to redesign and expand the role of the HR function and the system of workforce management practices in an attempt to capture the value described in the empirical HR strategy literature. Following the earlier logic in the article, we believe that the HR function's strategic role needs to focus more heavily on the workforce component of the firm's strategic capabilities. This will have important implications for how HR is managed and how it is evaluated in the organization. A focus on strategic capabilities will mean for HR professionals a much greater emphasis on differentiation. This will take the form not only of differentiation relative to competitors but also more differentiation within their own organizations. We believe that 
managers need to focus on how to align the HR systems and workforce investments at the level of the strategic business process. Such a focus requires disproportionate investments in "strategic" jobs and the need to increasingly differentiate employee performance within those jobs.

We believe that despite the substantial discussion in the academic and popular press about the importance of HR playing the role of "strategic partner" to line management, a considerable amount of variance remains in the capabilities of HR managers. In fact, in our own research we have found HR managers to be much more effective at the technical or operational aspects of HR's role than they were at strategy execution (Huselid, Jackson, \& Schuler, 1997), although the strategy execution had a much larger impact on firm performance. Addressing this issue effectively will require new research focused on clearly articulating the common body of knowledge, skills, competencies, and behaviors needed to be effective workforce strategy managers, for both those in HR as well as line roles.

Many authors have noted that the role of HR manager is a complex one, necessarily focused on meeting the needs of multiple constituencies (Ulrich \& Brockbank, 2005). These multiple roles and constituencies are likely to require multiple competencies from HR leaders as well. Unlike their colleagues in finance, accounting, and marketing, however, the vast majority of HR professionals do not have professional degrees or any type of certification in HR. As a consequence, it is perhaps unsurprising that they do not possess such broad competencies. Although the literature on general managerial competencies has a long history, the literature on the specific competencies needed for HR managers is much more limited. We believe that a useful line of research would blend the literatures on general manager and HR managers' competencies, with a specific focus on those competencies and behaviors directly related to strategy execution.

\section{Concluding Remarks}

In the past 15 years, the field of HR strategy has had a remarkable influence on both the academic literature and management practice. ${ }^{4}$ One of the purposes for writing this article is to highlight this important relationship between SHRM scholarship and management practice. In our view, it is what makes this line of inquiry both interesting (Bartunek, Rynes, \& Ireland, 2006) and influential (Bazerman, 2005). By comparison, consider earlier efforts to link HR decisions and firm financial performance, such as utility analysis that have largely disappeared from the literature. Despite this remarkable progress, the field of SHRM may be at a crossroads. The empirical literature demonstrating that HR could influence meaningful financial outcomes was once a novel and exciting result for managers. But that time has passed. To a substantial degree, managers now "get it" and do not have to be persuaded that the quality with which they manage the workforce has strategic impact. What they now need is help in understanding how to generate and sustain those potential returns.

Although academic research continues to replicate and refine these empirical results, the practice of HR strategy has moved beyond whether or not there is a significant return to better workforce management. Managers are asking questions like, "What are the key strategic positions in our organization, and how should they be managed?" and "How can we 
design and implement a workforce management system that helps us to execute strategy and create wealth?" This signals an evolution in the research problems confronting SHRM, as well as the foundation for an equally exciting 15 years going forward. Although the directions for future theoretical and empirical work discussed previously are rooted in an evolving academic literature, they are fundamentally influenced by the experience of managers who are attempting to implement these ideas. The most fundamental lesson from that experience is that although SHRM was initially an HR-centric paradigm, it is rapidly moving out of the hands of HR professionals into the hands of line managers and senior executives. HR professionals will play a role, but they may not be taking the lead.

The role of strategy implementation in the "black box" between the HR architecture and firm performance reflects this centrality of the line manager and the associated broader focus on workforce management. This shift in the SHRM axis within the firm needs to be reflected in SHRM research as well. Recent calls for evidenced-based management (Pfeffer \& Sutton, 2006) have emphasized the importance of incorporating the logic of academic research into managerial decision making as much as the empirical results. In our view, the logic of the HR-firm performance relationship has evolved during the past 15 years, and both scholarship and practice need to reflect that shift.

\section{Notes}

1. Several of the issues raised in this section were also discussed in Becker and Huselid (1998).

2. As an example of where this reliance on correlations yields misleading results, Wright, Gardner, Moynihan, and Allen describe the effects of controlling for an alternative explanation in one our studies (Huselid \& Becker, 1997). Using our correlation matrix, they calculate a partial correlation between human resource (HR) and firm performance that "reduces the observed correlation from .25 to .18" (p. 434). However, they fail to note that the regression coefficient for the HR index, which of course provides a much more complete control for alternative explanations, actually increased slightly when the additional control was included (Huselid \& Becker, 1997: 147, Table 1, cols. 3 and 6). Wright et al.'s observation that this partial correlation provides "at least some evidence for the possibility of a spurious correlation" (p. 434) is a considerable misinterpretation of our actual results.

3. These judgments, although admittedly subjective, are based on our experience in scores of organizations, both domestically and internationally, during the past 15 years.

4. One indication of strategic human resources management's academic impact is that among all of the articles published in the Academy of Management Journal since 1990, 3 of the 10 most highly cited articles are in the field of HR strategy.

\section{References}

Amit, R., \& Shoemaker, P. J. H. 1993. Strategic assets and organizational rent. Strategic Management Journal, 14(1): 33-46.

Barney, J. B. 2001. Is the resource-based "view" a useful perspective for strategic management research? Yes. Academy of Management Review, 26(1): 41-56.

Bartunek, J. M., Rynes, S. L., \& Ireland, R. D. 2006. What makes management research interesting, and why does it matter? Academy of Management Journal, 49(1): 9-15.

Bazerman, M. H. 2005. Conducting influential research: The need for prescriptive implications. Academy of Management Review, 30(1): 25-31. 
Becker, B. E., \& Huselid, M. A. 1998. High performance work systems and firm performance: A synthesis of research and managerial implications. Research in Personnel and Human Resource Management, 16: 53-101.

Becker, B. E., \& Gerhart, B. 1996. Human resources and organizational performance: Progress and prospects. Academy of Management Journal (Special Issue: Human Resources and Organizational Performance), 39(4): 779-801.

Becker, B. E., Huselid, M. A., \& Ulrich, D. 2001. The HR scorecard: Linking people, strategy and performance. Boston: Harvard Business School Press.

Colbert, B. A. 2004. The complex resource-based view: Implications for theory and practice in strategic human resource management. Academy of Management Review, 28(3): 341-358.

Collins, C. J., \& Smith, K. G. 2006. Knowledge exchange and combination: The role of human resource practices in the performance of high technology firms. Academy of Management Journal, 49: 544-560.

Combs, J. G., Ketchen, D. J., Jr., Hall, A. T., \& Liu, Y. 2006. Do high performance work practices matter? A metaanalysis of their effects on organizational performance. Personnel Psychology, 59: 501-528.

Cox, D. R. 1992. Causality: Some statistical aspects. Journal of the Royal Statistical Society, Ser. A, 155, pt. 2: 291-301.

Datta, D. K., Guthrie, J. P., \& Wright, P. M. 2005. Human resource management and labor productivity: Does industry matter? Academy of Management Journal, 48(1): 135-145.

Delery, J. E., \& Doty, D. H. 1996. Modes of theorizing in strategic human resource management: Tests of universalistic, contingent and configurational performance predictions. Academy of Management Journal, 39(4): 802-835.

Eisenhardt, K. M., \& Martin, J. A. 2000. Dynamic capabilities: What are they? Strategic Management Journal, 21 : 1105-1121.

Ericksen, J., \& Dyer, L. 2004. Toward a strategic human resource management model of high reliability organization performance. Working paper, Center for Advanced Human Resource Studies, Ithaca, NY.

Ethiraj, S. K., Kale, P., Krishnan, M. S., \& Singh, J. V. 2005. Where do capabilities come from and how do they matter? A study in the software services industry. Strategic Management Journal, 26: 25-45.

Ferraro, F., Pfeffer, J., \& Sutton, R. I. 2005. Economics language and assumptions: How theories can become selffulfilling." Academy of Management Review, 31(1): 8-24.

Gerhart, B. 2005. Human resources and business performance: Findings, unanswered questions, and an alternative approach. Management Revue, 16(2): 174-185.

Gerhart, B., Wright, P. M., McMahan, G. C., \& Snell, S. A. 2000. Measurement error in research on human resources and firm performance: How much error is there and how does it influence effect size estimates? Personnel Psychology, 53(4): 803-834.

Guest, D. E., Michie, J., Conway, N., \& Sheehan, M. 2003. Human resource management and corporate performance in the UK. British Journal of Industrial Relations, 41(2): 291-314.

Gulati, R. 1998. Alliances and networks. Strategic Management Journal, 19(4): 293-317.

Huselid, M. A. 1995. The impact of human resource management practices on turnover, productivity and corporate financial performance. Academy of Management Journal, 38(3): 635-672.

Huselid, M. A., Beatty, R. W., \& Becker, B. E. 2005. "A players" or “A positions?” The strategic logic of workforce management. Harvard Business Review, December: 110-117.

Huselid, M. A., \& Becker, B. E. 1997. The impact of high performance work systems, implementation effectiveness, and alignment with strategy on shareholder wealth. Academy of Management Best Papers Proceedings, 144-148.

Huselid, M. A., \& Becker, B. E. 2000. Comment on "Measurement error in research on human resources and firm performance: How much error is there and how does it influence effect size estimates?" by Gerhart, Wright, McMahan, and Snell. Personnel Psychology, 53(4): 835-854.

Huselid, M. A., Becker, B. E., \& Beatty, R. W. 2005. The workforce scorecard: Managing human capital to execute strategy. Boston: Harvard Business School Press.

Huselid, M. A., Jackson, S. E., \& Schuler, R. S. (1997). Technical and strategic human resource management effectiveness as determinants of firm performance. Academy of Management Journal, 40(1), 171-188.

Ittner, C. D., \& Larker, D. F. 2003. Coming up short on nonfinancial performance. Harvard Business Review, 81: 88-95.

Jackson, S. E., \& Schuler, R. S. 1995. Understanding human resource management in the context of organizations and their environments. Annual Review of Psychology, 46: 237-264. 
Lepak, D. P., \& Snell, S. A. 1999. The human resource architecture: Toward a theory of human capital allocation and development. Academy of Management Review, 24(1): 31-48.

Lepak, D. P., \& Snell, S. A. 2002. Examining the human resources architecture: The relationships among human capital, employment and resource configurations. Journal of Management, 28(4): 517-543.

MacDuffie, J. P. 1995. Human resource bundles and manufacturing performance-Organizational logic and flexible productions systems in the world auto industry. Academy of Management Journal, 48(2): 197-221.

Makadok, R. 2001. Toward a synthesis of the resource-based and dynamic-capability views of rent creation. Strategic Management Journal, 22: 397-401.

Makadok, R., \& Walker, G. 2000. Identifying a distinctive competence: Forecasting ability in the money fund industry. Strategic Management Journal, 21: 853-864.

Miles, R. E., \& Snow, C. C. 1994. Fit, failure and the Hall of Fame. New York: Free Press.

Osterman, P. 2006. The wage effects of high performance work organizations in manufacturing. Industrial and Labor Relations Review, 59(2): 187-204.

Pfeffer, J. 2005. Producing sustainable competitive advantage through the effective management of people. Academy of Management Executive, 19(4): 95-106.

Pfeffer, J., \& Sutton, R. I. 2000. The knowing-ding gap: How smart companies turn knowledge into action. Boston: Harvard Business School Press.

Pfeffer, J., \& Sutton, R. I. 2006. Hard facts, dangerous half-truths, and total nonsense: Profiting from evidencebased management. Boston: Harvard Business School Press.

Porter, M. 1985. Competitive advantage: Creating and sustaining superior performance. New York: Free Press.

Porter, M. 1996. What is strategy? Harvard Business Review, 74(November/December): 61-78.

Priem, R. L., \& Butler, J. E. 2001. Is the resource-based "view" a useful perspective for strategic management research? Academy of Management Review, 26(1): 22-40.

Raff, D. G. 2000. Superstores and the evolution of firm capabilities in American bookselling. Strategic Management Journal, 21(10/11): 1043-1060.

Ray, G., Barney, J. B., \& Muhanna, W. A. 2004. Capabilities, business processes, and competitive advantage: Choosing the dependent variable in empirical tests of the resource-based view. Strategic Management Journal, 25: 23-37.

Schuler, R. S. 1992. Strategic human resource management: Linking people with the needs of the business. Organizational Dynamics, 22: 19-32.

Schuler, R. S., \& Jackson, S. E. 1987. Linking competitive strategies with human resources practices. Academy of Management Executive, 1(3): 207-220.

Siggelkow, N. 2002. Evolution toward fit. Administrative Science Quarterly, 47: 125-159.

Skaggs, B. C., \& Youndt, M. 2004. Strategic positioning, human capital and performance in service organizations. Strategic Management Journal, 25: 85-99.

Teece, D. J., Pisano, G., \& Shuen, A. 1997. Dynamic capabilities and strategic management. Strategic Management Journal, 18(7): 509-533.

Thomas, K. W., \& Tymon, W. G., Jr. 1982. Necessary properties of relevant research: Lessons from recent criticisms of the organizational sciences. Academy of Management Review, 7: 345-352.

Ulrich, D., \& Brockbank, W. 2005. The HR value proposition. Boston: Harvard Business School Press.

Wright, P. M., Dunford, B. B., \& Snell, S. A. 2001. Human resources and the resource based view of the firm. Journal of Management, 27(6): 701-721.

Wright, P. M., Gardner, T. M., Moynihan, L. M., \& Allen, M. R. 2005. The relationship between HR practices and firm performance: Examining causal order. Personnel Psychology, 58: 409-446.

Wright, P. M., \& McMahan, G. 1992. Theoretical perspectives for strategic human resources management. Journal of Management, 18(2): 295-320.

Wright, P. M., \& Snell, S. A. 1998. Toward a unifying framework for exploring fit and flexibility in strategic human resources management. Academy of Management Review, 23(4): 756-772.

Youndt, M. A., \& Snell, S. A. 2004. Human resource configurations, intellectual capital, and organizational performance. Journal of Managerial Issues, 16(3): 337-360.

Zajac, E. J., Kraatz, M. S., \& Bresser, R. K. F. 2000. Modeling the dynamics of strategic fit: A normative approach to strategic change. Strategic Management Journal, 21: 429-453. 


\section{Biographical Notes}

Brian E. Becker is a professor of human resources in the School of Management at the State University of New York at Buffalo. He earned his $\mathrm{PhD}$ at the University of Wisconsin-Madison. His current research interests focus on the strategic impact of human resources.

Mark A. Huselid is a professor of human resource management in the School of Management and Labor Relations (SMLR) at Rutgers University. His current research interests focus on the linkages between workforce management and measurement systems, strategy execution, and firm performance. He was the editor of the Human Resource Management Journal from 2000 to 2004 and is a current or former member of numerous editorial boards. 